\title{
Underlying Gaps between Environmental Knowledge and Behavior in the City of Toyota
}

\author{
Hiroshi Ito ${ }^{1}$ \\ ${ }^{1}$ Department of Economics, Nagoya University of Commerce and Business, Nisshin, Japan \\ Correspondence: Hiroshi Ito, Faculty of Economics, Nagoya University of Commerce and Business, Nisshin, \\ Aichi, 470-0193, Japan. Tel: 81-561-73-2111. E-mail: hito@nucba.ac.jp
}

Received: October 18, 2016

Accepted: December 2, 2016

Online Published: December 20, 2016

doi:10.5539/ass.v13n1p82

URL: http://dx.doi.org/10.5539/ass.v13n1p82

\begin{abstract}
This study analyzes underlying gaps between environmental knowledge and behavior in the city of Toyota. Previous studies suggest that citizens' environmental knowledge of the eco-items comprising the city's eco-policy significantly improved since it was designated as an environmental model city by the Japanese government in 2009. However, citizens do not seem to act on these eco-items. By conducting a focus group interview with personnel from the largest environmental NPO working in Toyota, this study examines possible reasons why citizens do not take actions. The findings suggest that citizens may not act on the eco-items for both economic and ecological reasons as well as others. That is, citizens may not be convinced that the eco-items create enough ecological as well as economic benefits for practical application.
\end{abstract}

Keywords: Toyota City, eco-policy, environmental knowledge, environmental behavior

\section{Introduction}

The city of Toyota has been making considerable efforts to promote its eco-policy. The city has long been facing and addressing environmental issues in large part because of industrial activities by the Toyota Motor Corporation (TMC) and its affiliated companies. The city government elaborated on and implemented action plans to improve the environment in the 1990s and 2000s. Toyota was then designated by the Japanese government in 2009 as one of the environmental model cities (EMCs) (Toyota City, 2009).

Previous studies suggest that citizens' environmental knowledge of the eco-items comprising the city's eco-policy significantly improved since the EMC designation, but few citizens seem to actually act on these eco-items. For instance, a study on Toyota's eco-policy conducted by Ito and Kawazoe (forthcoming) showed that although some respondents recognized eco-items such as Ha:mo and the smart house, which will be described later, they do not use Ha:mo or live in the smart house. While their study identified gaps between environmental knowledge and behavior, it did not examine why citizens do not act on, even though they recognize the eco-policy items. The current research explores possible reasons for this lack of action through a focus group interview with members of an environmental NGO based in Toyota. They were selected as participants for this study because this is the largest environmental organization in Toyota and they have been working on environmental issues closely with the city government in Toyota. They are thus familiar with the city's eco-policy and are likely able to provide us with feasible explanations about the underlying knowledge-behavior gap.

This paper is organized as follows. I first explain the definitions of environmental knowledge, attitudes, and behaviors respectively, examining how they are possibly interrelated to each other. I then review the eco-items comprising the eco-policy of Toyota. I next describe the research methodology followed by the results. I end this paper with a discussion and conclusion drawn from the results.

\section{Literature Review}

\subsection{Environmental Knowledge}

Cheung et al. (2015) define environmental knowledge as the recognition of issues related to the environment and note that it is the source from which environmental attitudes are cultivated. They continue that "Individuals with a high level of EK would be expected to know what should be done to resolve environmental problems and understand the benefits of responsible behavior as it relates to the environment" (Cheung et al., 2015, p. 508). 
The attitude-behavior approach assumes that behavioral changes are brought about by increasing public knowledge about an issue (McKenzie-Mohr, 2012). The linear model that environmental knowledge leads to pro-environmental behaviors has been criticized because the reality is not likely to be that simple. Nonetheless, according to Kollmuss and Agyeman (2002), most environmental actors such as governments and NGOs "still base their communication campaigns and strategies on this assumption" (p. 246).

Robelia and Murphy (2012) argue that discussing how to mitigate the greenhouse effect, for example, "may not be meaningful if one has not encountered the term" (p. 301). Gifford and Nilsson (2014) also state that "making informed pro-environmental choices is difficult if one has incorrect or no knowledge" (p. 142). Therefore, knowledge should be one of the preconditions toward pro-environmental behavior (Jensen, 2002).

\subsection{Environmental Attitudes}

Environmental attitudes involve the psychological tendency of consumers to favor or disfavor some behaviors that are considered ecologically sustainable (Martinez et al., 2015). Environmental attitudes consist of environmental awareness and concern (Kollmuss \& Agyeman, 2002).

Environmental awareness is defined as a measure of one's ability to understand the nature of environmental processes and problems, his or her degree of concern for environmental quality, and the extent to which one is committed to environmental behavior in daily life (Yeung, 1998). Environmental concern refers to "the degree to which people are aware of problems regarding the environment and support efforts to solve them and/or indicate a willingness to contribute personally to their solution" (Dunlap \& Jones, 2002, p. 485).

Individuals with strong pro-environmental attitudes are more likely to engage in pro-environmental behavior (Kollmuss \& Agyeman, 2002) because as Olsson, Gericke, and Rundgren (2016) note, attitudes include behavioral as well as affective aspects.

\subsection{Environmental Behaviors}

Pro-environmental behaviors are environmentally friendly "behaviors that can contribute to reduction of current environmental burdens" (Kurisu, 2015, p. 1). In addition to reducing negative impacts on environment, some argue that pro-environmental behaviors imply behaviors or actions that intend to improve the environment. Steg and Vlek (2009) define pro-environmental behavior as "behavior that harms the environment as little as possible, or even benefits the environment" (p. 309). Sawitri et al. (2015) also note that pro-environmental behavior is "conscious actions performed by an individual so as to lessen the negative impact of human activities on the environment and to enhance the quality of the environment" (p. 28).

As seen above, environmental knowledge, attitudes, and behaviors are closely interconnected. The ultimate purpose of eco-policies is to enable citizens to acquire pro-environmental behavior, starting from gaining environmental knowledge and transforming it to behaviors through attitudes.

\subsection{Eco-policies in the City of Toyota}

This study focuses on three eco-themes that Toyota supports to promote its eco-policy: transportation, the urban center, and public welfare and livelihood because these three are the most familiar eco-themes to citizens (Ito and Kawazoe, forthcoming). Transportation variables consist of knowledge of next generation cars (NGCs) and Ha:mo. NGCs include electric vehicles (EVs), hybrid electric vehicles (HEVs), and plug-in hybrid vehicles (PHVs). EVs are cost-efficient because the electricity costs less than oil fuel. PHVs have rechargeable batteries and standard combustion engines, which allows cars to drive two to four times more with the same amount of gasoline (Woo et al., 2012). Ha:mo consists of NAVI, an information system that supports low-carbon, seamless mobility and RIDE, a car sharing system that uses compact electric vehicles for urban short-distance transportation.

The urban center variables consist of knowledge of Ecoful Town and the heat island effect. Ecoful Town, established in 2012, is a pavilion showcasing eco-living that demonstrates how Toyota tackles challenges and elaborates on eco-strategies including transportation, the urban center, and public welfare and livelihoods toward a low-carbon society. Visitors to Ecoful Town can have hands-on experiences such as riding an EV and visiting a smart house. Heat island effect is the phenomena of temperature in the urban areas being higher than that of temperatures in sub-urban areas. This is caused by excess population, developed industries, use of cars, congested and tall buildings, asphalt roads, and cement squares (Gao et al., 2015).

Public welfare and livelihood variables consist of the smart house and eco-points. The smart house is a residential building that pursues reducing $\mathrm{CO}_{2}$ gas emission and saving energy through the use of renewable energy sources and monitoring of energy consumption (Kim et al., 2015). The smart house in Toyota is 
characterized with a home energy management system (HEMS) that can monitor energy generation and consumption. Toyota has promoted the Eco-Family Card with "eco-points" that can be exchanged for certain products. When registered citizens purchase an ecological product with the Eco Family Card at a greenly affiliated store or recycle something at a designated place, they can receive points. Once a certain number of points have accumulated, they can be exchanged for certain goods, such as stationery, bus tickets, or gift certificates.

A previous study conducted through surveys with 271 respondents around Toyota City station in June 2016 showed that there are quite a few citizens who know about the above-stated eco-items, but they do not actually act on them (see Ito and Kawazoe, forthcoming, for details). For instance, only one respondent actually reported that she lived in the smart house, and no respondent reported that they ever used Ha:mo. There were 27 respondents who actually drove NGCs, 16 respondents who had been to Ecoful Town, 15 respondents who used eco-points, and 10 respondents who used greening as a countermeasure against the heat island effect. The current research thus examines why most citizens do not act on eco-items despite their knowledge about them.

\section{Methodology}

\subsection{Sample}

The participants of this study are members of an environmental NPO headquartered in Toyota. They were targeted for this study because this is the largest environmental NPO in Toyota and they have been working on addressing environmental issues with the city government and thus are familiar with the city's eco-policy and are likely to be able to provide feasible explanations about why citizens do not act on, while knowing, the eco-items comprising the eco-policy.

The president of the NPO helped the author to arrange the focus group interview. He inserted a brochure in a monthly newsletter describing the research and requesting potential interviewees. The newsletter was distributed to relevant stakeholders who are involved in eco-activities of the NPO. In total, six individuals (three males and three females, all over 40 years old) participated in the focus group. Each participant was compensated 2,000 yen (or the equivalent for 20 USD).

\subsection{Focus Group}

A focus group interview is a particular kind of group interview. As Cohen et al. (2011) explain that a focus group interview encourages the interaction of a group who discuss a topic provided by the researcher, leading toward a collective view. Thus, "[i]t is from the interaction of the group that the data emerge...to discuss a particular given theme or topic, where the interaction with the group leads to data and outcomes" (p. 436). Breen (2006) explains that a focus group interview is employed to "to generate [new] ideas for the purpose of devising recommendations for future change" (p. 464).

The number of participants for this study was six. This number falls into the range often suggested in the literature for focus group. Rabiee (2004), for example, notes: "the number generally suggested as being manageable is between six and ten participants; large enough to gain variety of perspectives and small enough not to become disorderly or fragmented" (p. 656). Krueger (2002) also suggests a similar number of participants for a focus group, but between six and eight are preferred.

The group should have homogeneity of background in the required research area: otherwise the discussion will lose focus (Rabiee, 2004). This study meets that criterion as well: all the participants are involved in eco-activities with the same environmental NPO in Toyota.

\subsection{Procedure}

At the beginning of the focus group discussion, the author provided the context of why this study was being conducted. The participants then filled out the questionnaires that asked whether they knew about certain eco-items comprising the eco-policy and whether they acted on these items (Table 1).

After filling out the questionnaire, respondents were asked why they were aware of certain items or not, and why they act or do not act on these items. For instance, they were asked why those who already have NGCs decided to buy them. Is it for economic reasons (e.g., eco-friendly cars are energy efficient and economical) or environmental reasons (e.g., eco-friendly cars produce less $\mathrm{CO}_{2}$ )? Similarly, why are some respondents not considering purchasing NGCs? Is it for economic reasons (e.g., eco-friendly cars are initially more expensive than gas fuel vehicles) or environmental reasons (e.g., not having cars is the most environmental friendly)? Similar questions and discussions occurred regarding the reasons for acting, or not acting, on other items such as Ha:mo and eco-points. 
Table 1. Questionnaire items

\begin{tabular}{ll}
\hline Eco-theme & Survey Questions \\
\hline Transportation & Q1. Do you know about NGCs? \\
& Q2. Do you ride NGCs? \\
Q3. Do you know about Ha:mo? & Q4. Have you used Ha:mo? \\
Urban Center & Q5. Do you know about the heat island effect? \\
& Q6 Do you take measures against the heat island effect? \\
& Q7. Do you know about the Ecoful Town? \\
Q8. Have you been to the Ecoful Town? & Q9. Do you know about the smart house? \\
& Q10. Do you live in the smart house? \\
& Q11. Do you know about eco-points? \\
& Q12. Do you use eco-points?
\end{tabular}

The focus group took two hours. The length of the discussion also fits within the range often suggested in the literature (Rabiee, 2004). The participants were all familiar with each other and the interviewing place because the focus group took place in the environmental NPO's building where they work. Therefore, assumably, they were comfortable in giving their opinions during the focus group interview.

\section{Results}

\subsection{Next Generation Cars (NGCs)}

Among the participants, only one participant actually drives an NGC. He is satisfied with his NGC because he spends little money on gas: "I go to the gas station only every three month. The owner of the gas station is a friend of mine, and he is now mad at me because I hardly go there."

One participant, who did not own an NGC, showed a concern about the possible defects of NGCs: "the systems of NGCs are supposed to be more complicated than gas fuel cars and may thus be easier to break or more difficult to repair." She was also concerned about the lifespan of the lithium battery installed in NGCs: "If we have to replace the battery with a new one within 10 years, it will neither be economical nor ecological." Whereas she recognizes the advantages unique to NGCs such as storing and provision of electricity, "I prefer to wait and see until everyone around me will have NGCs."

Another participant mentioned an economic benefit of not having NGCs: "Gas fuel cars are still much cheaper than NGCs. Also, light-weight, gas-efficient cars are almost as energy efficient as NGCs. That is, gas fuel cars can be more economical than and as ecological as NGCs."

Another participant claimed that she finds it easier to drive a light gas fuel car: "For example, Prius [TMC's $\mathrm{PHV}]$ is too big and hard to drive. If we have car accidents because of difficulty in driving NGCs, what is the point of driving them? For safety reasons, I prefer to drive a light-weight, gas-efficient car."

\subsection{Ha:mo}

There were two participants who did not know about Ha:mo. Those who knew about Ha:mo said that they came to know it via the mass media such as TV or newspapers when it was built. Yet, all participants said that many people around them do not know about it yet. One participant reported: "While Ha:mo is established around the Toyota City Station and people often see it, they don't know what it is. Ha:mo has not been promoted well by the city government." This participant continued to argue: "If people have their own cars, they do not consider using Ha:mo. Why do they have to go all the way to the Ha:mo station to rent EVs and go back to leave them again in the station?"

One participant said that if there were Ha:mo in the city center of Tokyo or Nagoya where millions of people live, instead of Toyota, it would have been more popular. However, Toyota, with a population of fewer than 500,000 and more than $90 \%$ of households owning cars, is not suitable for a transportation system like Ha:mo. One participant said: "Unless Ha:mo is located nearby, no one would use it." 


\subsection{Heat Island Effect}

Some participants said that the term heat island effect was popular in Japan a decade ago but not anymore. One participant said: "Nowadays, the term heat island effect has been replaced with or included in the term climate change or global warming. With regard to greening, a common measure to be taken against the heat island effect, one participant said: "green curtains [shade made by plants] are becoming popular and we now often see them even in ordinary houses in Toyota."

\subsection{Ecoful Town}

All participants have been to Ecoful Town. They went there for various reasons. All female participants said that they went there to have coffee or lunch with their female friends at a restaurant called Hogaraka, which serves local organic food, located inside Ecoful Town. A previous study indicated that Hogaraka was popular among women in their twenties (Ito, 2014). The current research suggests that Hogaraka may be popular with women across various ages, as all participants for the current study are over 40 years old. One female participant said that Hogaraka became popular among women due to word of mouth.

A male participant said that he sometimes goes there because he likes to walk and passes by Ecoful Town. However, all participants said that Ecoful Town may not be an adequate place for family with children because there is no place where children can play around or enjoy themselves.

\subsection{Smart House}

No participant claimed that they lived in the smart house. Some participants, however, said that they have installed solar panels and LED lights, though not HEMS. One participant asked: "What is the precise definition of the smart house? My house may not be the smart house because there is no HEMS, but we have solar panels and the cost of electricity is absolutely zero." Another participant said that the city government should subsidize not only citizens buying the smart house but also those who install solar panels or even LED lights because they involve, at least partially, smart house components.

\subsection{Eco-points}

Eco-points have been introduced and promoted by the city government during civic events. According to the participants, however, many people do not know how to use the eco-points. One participant claimed: "those who are not interested in protecting the environment would not participate in eco-related civic events and will not know about it."

Another participant pointed out: "While I enjoy collecting points, the process of the registration may be found troublesome. Those who want to use eco-points need to take some time to register to get the eco-point card called the Eco-family Card, collect eco-points by doing eco-activities or buying eco-products, and use them at stores greenly affiliated with the city government. Many people, especially the rich people who may not be interested in the subtle benefits of having eco-points, would probably not do it because they find it troublesome."

\section{Discussion}

This study examined why Toyota citizens may not act on eco-items comprising the eco-policy while they recognize these items. Findings suggest that citizens do not act on the eco-items for economic, ecological and other reasons. For example, while driving an NGC can be ecological and economical due to its energy efficiency. NGCs are more expensive at the time of purchase and do not have up front economic benefits. Also, some participants believe that they are acting environmentally friendly by not driving NGCs, given the assumed short life span of the lithium battery. Driving a light gas fuel car can be more ecological, more economical, and easier to drive. Likewise, while no participant lives in the smart house, they believe that they are at least partially, acting on the smart house item by installing solar panels and LED lights. They believe that the city government should provide more subsidies to citizens with intentions of installing smart house items.

Regarding Ha:mo, while they recognize the benefit of using it for the environment, they find it too troublesome to actually use. There are few convenient Ha:mo stations where they can rent and leave EVs. It might be used more if a network of stations was created that better coincides with the daily lives of citizens. Less troublesome than Ha:mo, eco-points were used by all participants in this study; however, they suggested that the eco-point registration and usage process might be too troublesome for other citizens to go through the process of acquiring it and using it.

Unlike the four eco-items discussed above, Ecoful Town and the heat island effect have been acted on relatively highly: more and more citizens go to Ecoful Town and green curtains are increasingly common. The participants believe that these two items will gain more popularity in the future. 


\section{Conclusion}

To facilitate the use of the rest of the eco-items that have not been acted on, the following is suggested: the development of cheaper and smaller NGCs which are easier to drive; the extension of the definition of the smart house, and more governmental support for the installation of smart house items such as solar panels and LED lights; more installation of Ha:mo stations; and a simpler process of registration for eco-point cards.

Possible reasons that citizens do not act on eco-items are not solely ecological or economic but a mixture of both ecological and economic reasons and some other factors (e.g., safety, convenience). Also, it seems that citizens may not be fully engaged in the 'eco-items' defined by Toyota; yet a closer look at their actions suggests that they are taking actions in ways that approximates "eco-items." For instance, not many citizens may own the smart house, but they are making upgrades to their houses to make them more environmentally friendly. Perhaps Toyota needs to broaden the ways that their eco-items can be achieved. Along with NGCs, driving light-weight gas-efficient vehicle could be included in the transportation theme.

\section{Future Research}

The participants for this study, as those who work in the field of environmental protection, are naturally aware of issues with the eco-items comprising the eco-policy. Yet, general citizens may have different perspectives on these items. Semi-structured interviews with citizens about the city's eco-policy could help us understand more about why citizens know about certain aspects of the policy and how actions related to the policy could be better promoted. Also, another focus group interview dedicated to asking respondents about what eco-items they think could be added to Toyota's eco-policy would be useful. This could clarify how citizens may take actions that approximate existing eco-items.

\section{Acknowledgments}

I would like to thank Mr. Ryuji Sakamoto for his support to this study. I am also grateful to Mr. Ezra Anton Greene for editing this paper.

\section{References}

Breen, R. L. (2006). A Practical Guide to Focus-group Research. Journal of Geography in Higher Education 30(3): 463-475. DOI: 10.1080/03098260600927575

Cheung, L. T. O., Fok, Lincoln, Tsang, E. P. K., Fang, W., \& Tsang, H. Y. (2015). Understanding Residents' Environmental Knowledge in a Metropolitan City of Hong Kong, China. Environmental Education Research, 21(4): 507-524. DOI: 10.1080/13504622.2014.898247

Cohen, L., L. Manion, \& Morrison, K. (2011). Research Methods in Education. London and New York: Routledge.

Dunlap, R. E., \& Jones, R. (2002). Environmental Concern: Conceptual and Measurement Issues. In Dunlap \& Michelson (Eds.), Handbook of Environmental Sociology (PP. 482-542). London: Greenwood Press.

Gao, R. D., Xu, Q. F., Li, X. M., \& Wang, H. (2015). Influence of Urban Heat Island Effect on Sulphate Attach on Concrete. Materials Research Innovations, 19, 229-235. DOI: 10.1179/1432891715Z.0000000001972

Gifford, R., \& Nilsson, A. (2014). Personal and Social Factors That Influence Pro-environmental Concern and Behavior: A Review. International Journal of Psychology, 49(3), 141-157. DOI: 10.1002/ijop.12034

Gleisner, B. B., \& Weaver, S. A. (2006). "Cars, Carbon, and Kyoto: Evaluating an Emission Charge and Other Policy Instruments as Incentives for a Transition to Hybrid Cars in New Zealand." Kltuitui: New Zealand Journal of Social Sciences Online, 1, 81-89. DOI: 10.1080/1177083X.2006.9522412

Ito, H. (2014). Toyota as an Environmental Model City. Is its Eco-policy Recognized? Journal of Sustainable Development, 7(2), 70-77. DOI: 10.5539/jsd.v7n2p70

Ito, H., \& Kawazoe, N. (forthcoming). A Review of Toyota City's Eco-policy: Changes of citizens' awareness between 2012 and 2015. Urban Research and Practice, 11(1). DOI: 10.1080/17535069.2016.1254676

Jensen, B. B. (2002). Knowledge, Action and Pro-environmental Behavior. Environmental Education Research, 8(3), 325-334. DOI: $10.1080 / 13504620220145474$

Kim, S-K., Lee, S-J., Kwon, H. J., \& Ahn, M. (2015). Zero-energy Home Development in Korea: Energy-efficient and Environmentally Friendly Design Features and Future Directions. Housing and Society, 42(3), 222-238. DOI: 10.1080/08882746.2015.1121682

Kollmuss, A., \& Agyeman, J. (2002). Mind the Gap: Why do People Act Environmentally and What are the 
Barriers to Pro-environmental Behavior? Environmental Education Research, 8(3), 239-260. DOI: $10.1080 / 13504620220145401$

Krueger, R. A. (2002). Designing and Conducting Focus Group Interviews. Retrieved from http://www.eiu.edu/ihec/Krueger-FocusGroupInterviews.pdf

Kurisu, K. (2015). Pro-environmental Behaviors. Tokyo, Heidelberg, New York, Dordrecht, and London: Springer.

Martinez, C. P., Castaneda, M. G., Marte, R. B., \& Roxas, B. (2015). Effects of Institutions on Ecological Attitudes and Behasvior of Consumers in a Developing Asian Country: The Case of the Philippines. International Journal of Consumer Studies, 39, 575-585. DOI: 10.1111/ijcs.12188

McKenzie-Mohr, D. (2012). Fostering Sustainable Behavior: An Introduction to Community-based Social Marketing. British Columbia: New Society Publishers.

Olufemi, A. C., Mji, A., \& Mukhola, M. S. (2016). Assessment of Secondary School Students' Awareness, Knowledge and Attitudes to Environmental Pollution Issues in the Mining Regions of South Africa: Implications for Instruction and Learning, Environmental Education Research, 22(1), 43-61. DOI: $10.1080 / 13504622.2014 .984162$

Rabiee, F. (2004). Focus-group Interview and Data Analysis. Proceedings of the Nutrition Society, 63, 655-660. DOI: $10.1079 / \mathrm{PNS} 2004399$

Robelia, B., \& Murphy, T. (2012). What do People Know about Key Environmental Issues? A Review of Environmental Knowledge Surveys. Environmental Education Research, 18(3), 299-321. DOI: $10.1080 / 13504622.2011 .618288$

Steg, L., \& Vlek, C. (2009). Encouraging Pro-environmental Behavior: An Integrative Review and Research Agenda. Journal of Environmental Psychology, 29, 309-317. DOI: 10.1016/j.jenvp.2008.10.004

Sawitri, D. R., Hadiyanto, H., \& Hadi, S. P. (2015). "Pro-environmental Behavior from a Social Cognitive Theory Perspective." Procedia Environmental Sciences, 23, 27-33. DOI: 10.1016/j.proenv.2015.01.005

Toyota City. (2009). Summary of Action Plans towards an Environmental Model City. Retrieved from http://www.city.toyota.aichi.jp/division/an00/an06/1252190/02gaiyou.pdf

Woo, G. M. S., Mak, C. M., Cheng, C. Y., \& Li, J. (2012). The Conversion of a Hybrid Electric Vehicle into a Plug-in Hybrid Electric Vehicle. Journal of International Council on Electric Engineering, 2(2), 178-186. DOI: $10.5370 / J I C E E .2012 .2 .2 .178$

\section{Copyrights}

Copyright for this article is retained by the author(s), with first publication rights granted to the journal.

This is an open-access article distributed under the terms and conditions of the Creative Commons Attribution license (http://creativecommons.org/licenses/by/4.0/). 